\title{
Propósitos
}

\section{de las actuaciones} \section{administrativas en prácticas} comerciales restrictivas y significatividad*

\author{
Moderador: Mauricio Velandia Castro ${ }^{1}$ \\ Panelistas: José Miguel de la Calle Restrepo2 \\ Gustavo VAlBuEna QuiÑONES ${ }^{3}$
}

* DOI: https://doi.org/10.18601/01236458.n54.03

1 Mauricio Velandia Castro. Profesional en Derecho y Especialista en Derecho Contractual y Relaciones Jurídico-Negociales, Universidad Externado de Colombia, Especialista en Legislación Financiera, Universidad de los Andes, y becario para adelantar una práctica en la Superintendencia de Bancos Valores y Seguros de México.

Se ha desempeñado como jefe de la División para Promoción de la Competencia Superintendencia de Industria y Comercio (1998-2000), socio de la firma Mauricio Velandia Abogados S.A.S. (2001 a la fecha), Árbitro lista A Cámara de Comercio de Bogotá (2005 a la fecha), Árbitro lista A Cámara de Comercio de Medellín (2008 a la fecha), profesor de universidades nacionales y extranjeras en temas de competencia, consumo, responsabilidad y canales de distribución.

2 José Miguel de la Calle Restrepo. Abogado egresado de la Universidad del Rosario con Maestría en Derecho (LLM) de Harvard University, de 1993, y estudios de economía y Derecho del London School of Economics y el Instituto Ortega y Gasset de España. Entre los años 2010 y 2012 fungió como Superintendente de Industria y Comercio, entidad que oficia como autoridad única de competencia, oficina nacional de protección de datos, autoridad de protección al consumidor y registro nacional de propiedad industrial, entre otros aspectos. Actualmente es socio de la firma de abogados Garrigues y director de las áreas de Derecho público y Derecho de la competencia. Ha sido conjuez de la Corte Constitucional y es miembro activo de la lista A de árbitros del Centro de Arbitraje y Conciliación de la Cámara de Comercio de Bogotá. Autor de libros en las áreas de Justicia y Protección de Datos, y columnista regular de periódicos especializados.

3 Gustavo Valbuena Quiñones. Abogado, de la Universidad de los Andes, LLM en Derecho Europeo e Internacional de Negocios (énfasis Derecho público económico) de la Universidad París II PanthéonAssas (Institut de Droit Comparé), magíster (DEA) en Derecho Público Interno de la Universidad Paris I Panthéon - Sorbonne y especialista (DSU) en Derecho Administrativo de la Universidad PanthéonAssas Paris II. Abogado admitido al ejercicio profesional en Francia. Ha sido Superintendente de Industria y Comercio. Ha sido asesor de la Secretaría Jurídica de la Presidencia de la República, Miembro del Consejo Asesor del Superintendente Financiero de Colombia, Gerente Jurídico nacional de La Previsora S.A. Compañía de Seguros, asesor del Ministerio de Hacienda y Crédito Público. Actualmente ejerce la práctica profesional desde la firma Valbuena Abogados. Ha sido profesor de las universidades de Los Andes, Nuestra Señora del Rosario y Externado de Colombia, autor de varios escritos académicos vinculados al Derecho de la competencia y las telecomunicaciones. Miembro 


\section{INTRODUCCIÓN}

El artículo 3 de la Ley 1340 de 2009 indica que la Superintendencia de Industria y Comercio dará trámite a aquellas denuncias que resulten significativas para alcanzar ciertos propósitos, dentro de los que se encuentran "la libre participación de las empresas en el mercado, el bienestar de los consumidores y la eficiencia económica", y los tendrá en cuenta "al momento de resolver sobre la significatividad de la práctica e iniciar o no una investigación, sin que por este solo hecho se afecte el juicio de ilicitud de la conducta".

En mi opinión, esta es la norma más importante en materia de competencia, porque hace referencia a un juicio de responsabilidad, y en ese contexto, se debe "salir" de las normas de competencia y acudir a las normas generales de la responsabilidad, partiendo de la premisa según la cual el Derecho de la competencia no está conformado por una descodificación libre y autónoma, lo que iría en contra de todo lo que ha dicho la Corte Constitucional en torno a la armonización y sistematización del Derecho ${ }^{4}$.

Ahora bien, cuando la Superintendencia de Industria y Comercio abre una investigación lo hace porque es solamente típica y sanciona porque es típica y eso no es un juicio de responsabilidad, eso es una connotación de tipicidad. Entonces, ¿dónde queda la responsabilidad sancionatoria administrativa?, ¿cuáles son las variables que tiene que analizar cualquier ente administrativo que ejerza actividades de policía administrativa?

En materia de responsabilidad, diríamos que el comportamiento debe ser típico, antijurídico y culpable para que haya juicio de responsabilidad. Cuando se dice, por ejemplo, que la Superintendencia tiene la autonomía para verificar cuándo investiga y qué investiga pareciera ser discriminatorio y dicha interpretación estaría en contra de la Constitución Política, porque sería violatoria del derecho a la igualdad ${ }^{5}$. La interpretación que más se acerca a la Constitución es la que indica que se debe observar si un comportamiento verdaderamente encuadra en la responsabilidad, esto es, que el comportamiento debe ser típico, es decir, establecido en la ley; antijurídico, que daña un bien jurídico tutelado, y culpable.

de la Comisión Redactora del Código de Procedimiento Administrativo y de lo Contencioso Administrativo (actual Ley 1437 de 2010).

$4 \mathrm{Al}$ respecto, entre otras, sentencias T-425 del 26 de septiembre de 1995 y C-284 del 15 de mayo de 2015.

5 Artículo 13 de la Constitución Política. "Todas las personas nacen libres e iguales ante la ley, recibirán la misma protección y trato de las autoridades y gozarán de los mismos derechos, libertades y oportunidades sin ninguna discriminación por razones de sexo, raza, origen nacional o familiar, lengua, religión, opinión política o filosófica. El Estado promoverá las condiciones para que la igualdad sea real y efectiva y adoptará medidas en favor de grupos discriminados o marginados. El Estado protegerá especialmente a aquellas personas que, por su condición económica, física o mental, se encuentren en circunstancia de debilidad manifiesta y sancionará los abusos o maltratos que contra ellas se cometan". 
Por otra parte, respecto del artículo 3 de la Ley 1340 de 2009, la Corte Constitucional en un Auto de $2013^{[6]}$ llegó a concluir que dicha norma estaba derogada, posición que no compartimos en la sustancia, ya que el Decreto 4886 de 2011 dentro de las funciones de la Superintendencia de Industria y Comercio expresamente señala que una de ellas es la de "conocer en forma privativa de las reclamaciones o quejas por hechos que afecten la competencia en todos los mercados nacionales y dar trámite a aquellas que sean significativas para alcanzar en particular, los siguientes propósitos: la libre participación de las empresas en el mercado, el bienestar de los consumidores y la eficiencia económica"7.

Con esta introducción del artículo 3 de la Ley 1340 de 2009, resulta importante abrir un debate sobre ello.

\section{EL ALCANCE Y CONTENIDO DE LA SIGNIFICATIVIDAD}

¿Los propósitos descritos en el artículo 3 de la Ley 1340, que bablan de significatividad, contienen la antijuridicidad del tema de libre competencia, bien jurídico tutelado, o son un factor de competencia para que la Superintendencia conozca y falle, o sea juez natural, o ninguno de los anteriores? y ila antijuridicidad aplica para los carteles verticales $u$ borizontales?

\section{José Miguel de la Calle Restrepo}

La aproximación del doctor Mauricio es muy interesante y polémica, al traer de un ámbito del Derecho penal donde es más natural la visión tripartida de tipicidad, antijuridicidad y culpabilidad al ámbito de competencia. Esa figura de la antijuridicidad es muy interesante, es una aproximación útil que puede traer avances en la doctrina; sin embargo, es tratar de "acomodar una camisa ajena" a un terreno donde la legislación y la doctrina no se han movido. En realidad, el desarrollo doctrinal y legislativo del mundo de la competencia se ha concentrado en un terreno distinto.

Abordando de manera más específica el tema de la significatividad, que aun cuando puede no resultar ser el más importante para el Derecho de la competencia, sí es fundamental, porque es la marca la entrada al sistema, y eso la convierte en una institución particularmente relevante. En este punto, es importante advertir que la Superintendencia de Industria y Comercio, como autoridad única de competencia, es la que tiene el poder de "cerrar o abrir la llave" al sistema. Por eso me anticipo a algunas críticas al desarrollo doctrinal de la Superintendencia respecto de este tema, porque no ha sido clara, coherente y estable en la doctrina, generando cierta inseguridad jurídica para saber cuándo, cómo, en qué circunstancias y quién puede acceder al sistema.

Ahora bien, respondiendo la pregunta, la figura de la antijuridicidad contiene un elemento positivo y es que el análisis no puede quedarse en la tipicidad. La antijuridicidad 
para los penalistas es un factor que, más allá de encuadrar la conducta en el concepto típico del código penal, analiza si el comportamiento lesiona un bien jurídico tutelado o, por el contrario, hace parte de un ámbito excluido de la sanción. Es decir, no basta con analizar si la conducta desplegada por el investigado se encuadra en la descripción normativa, sino que, debe realizarse ese análisis adicional.

Esto resulta bastante interesante $y$, trayéndolo al ámbito de competencia, nos conduce al análisis del "objeto-efecto", y a precisar si el comportamiento, más allá de encontrarse en la tipificación de alguna de las prácticas contrarias a la competencia, responde a la pregunta de si lesiona o no, o genera grave peligro para un bien jurídico, lo que nos obliga en el ámbito de la competencia a precisar cuál es el bien jurídico de cada uno de los comportamientos repudiables y a hacer un análisis adicional.

Ahora bien, existe mucho valor agregado en el análisis de la antijuridicidad, pero el desarrollo legal colombiano, particularmente del parágrafo del artículo 3 de la Ley 1340 de 2009 que refiere que "la Superintendencia de Industria y Comercio tendrá en cuenta los propósitos de los que trata este artículo al momento de resolver la significatividad de la práctica a iniciar o no una investigación, sin que por este solo hecho se afecte el juicio de ilicitud de la conducta".

A pesar de que pudiera resultar interesante el análisis de la antijuridicidad, con la parte final de la norma, se debe forzosamente concluir que, en Colombia, a pesar de que una conducta no sea significativa puede ser ilícita. Ello indica que, y podría ser anulable por un proceso de nulidad en la jurisdicción contenciosa administrativa o ser susceptible de otro tipo de investigación y sanciones, por ejemplo, responsabilidad civil. Con ello, se concluye que una práctica que no se considere significativa puede ser susceptible de nulidad y de condena por perjuicios, aun cuando en Colombia no ha hecho carrera la responsabilidad civil por competencia.

Así pues, la significatividad que marca el acceso al sistema de competencia que vigila la Superintendencia de Industria y Comercio, no es una definición sobre la ilicitud del acto para muchos otros efectos que esto pueda conllevar.

Entonces, queda como conclusión que la antijuridicidad resulta ser un ejercicio interesante que se convierte en teórico, porque la ilicitud no se convierte en sinónimo de tipicidad, dado que cuando la norma indica que "se salva la ilicitud", se está refiriendo a la posibilidad de sancionar por alguna otra razón. Es decir que, respecto a la premisa tipicidad, antijuridicidad y culpabilidad es igual a la posibilidad de sancionar, entendería que esta expresión ilicitud se equipara a que es sancionable por otros ámbitos del derecho una conducta así no sea significativa.

\section{Gustavo Valbuena Quiñones}

Como lo demostró el doctor Mauricio con su introducción, la significatividad es un tema complejo respecto del cual, hace falta aún mucha reflexión. Definitivamente, la significatividad no se equipara a la antijuridicidad y no solo porque la antijuridicidad esté más vinculada a la ilicitud y la significatividad más al acceso al sistema, sino porque 
expresamente, desde el artículo 19 de la Ley 155 de $1959^{[8]}$ y hoy en el artículo 46 del Decreto 2153 de $1992^{[9]}$, la calificación es clara en cuanto a que las conductas que sobrevengan las disposiciones sobre acuerdos, actos y abusos de posición dominante, están impregnadas de objeto ilícito y, en consecuencia, serían anulables dentro del escenario que sea, por ejemplo, el del juez del contrato, el del juez administrativo.

Tienen un vicio que no impone para su declaración un análisis de significatividad. Lo anterior, porque el análisis de una conducta que contraviene las normas de competencia no necesariamente tiene que incorporar la significatividad, pues esta tiene que ver más con el plan de trabajo de la Superintendencia.

Si se revisa la redacción de "alcanzar los propósitos" del Decreto 2153 de 1992 y la que quedó en la Ley 1340 de 2009, hubo una eliminación voluntaria de una coma ${ }^{10}$ y quedó vinculado el tema de significatividad con el propósito de alcanzar esos tres cometidos, calificados por la ley como propósitos de este tipo de actuaciones: el bienestar del consumidor, la eficiencia económica y la libre participación de las empresas en el mercado.

Cuando se debatía la ley y se hacía el planteamiento sobre si debía quedar o no la palabra "significatividad" en el artículo 3, existió un caso en la Superintendencia que no trascendió relacionado con un posible acuerdo de precios entre unos panaderos en un pueblo de Boyacá. Con base en el entendimiento que había de la palabra significatividad se vinculó la significatividad al "peso" que podía tener un acuerdo específico en un pueblo de Boyacá y con base en esa falta de significatividad no se abrió investigación.

Luego, cuando se debate el tema de la ley, considero que fue un error en ese momento vincular la significatividad al "peso específico dentro del mercado relevante", porque realmente la significatividad que refiere la Ley 1340 de 2009, tiene más relación con el plan de trabajo de la Autoridad Única de Competencia, pues se refiere a cuando una decisión de la Superintendencia de Industria y Comercio puede llegar a

8 Artículo 19 de la Ley 155 de 1959. "Los acuerdos, convenios u operaciones prohibidas por esta Ley, son absolutamente nulos por objeto ilícito".

9 Artículo 46 del Decreto 2153 de 1992. "En los términos de la Ley 155 de 1959 y del presente Decreto están prohibidas las conductas que afecten la libre competencia en los mercados, las cuales, en los términos del Código Civil, se consideran de objeto ilícito. (...)".

10 Versión original del artículo 2.1 del Decreto 2153 de 1992: "Velar por la observancia de las disposiciones sobre promoción de la competencia y prácticas comerciales restrictivas, en los mercados nacionales sin perjuicio de las competencias señaladas en las normas vigentes a otras autoridades; atender las reclamaciones o quejas por hechos que afecten la competencia en los mercados y dar trámite a aquellas que sean significativas, para alcanzar, en particular, las siguientes finalidades: mejorar la eficiencia de aparato productivo nacional, que los consumidores tengan libre escogencia y acceso a los mercados de bienes y servicios, que las empresas puedan participar libremente en los mercados; $y$, que en el mercado exista variedad de precios y calidades de bienes y servicios (destacado fuera del original). Artículo 3 de la Ley 1340 de 2009: Velar por la observancia de las disposiciones sobre protección de la competencia; atender las reclamaciones o quejas por hechos que pudieren implicar su contravención y dar trámite a aquellas que sean significativas para alcanzar en particular los siguientes propósitos: la libre participación de las empresas en el mercado, el bienestar de los consumidores y la eficiencia económica" (destacado fuera del original). 
recorrer una milla más en alcanzar esos tres propósitos: el bienestar del consumidor, la eficiencia económica o la libre participación de las empresas en el mercado. Pueden existir conductas que, no obstante, referirse a un pequeño mercado relevante que no tengan trascendencia nacional, sí pueda llevar a cumplir propósitos asociados a estas tres finalidades.

En 2017, la Superintendencia de Industria y Comercio abrió varias investigaciones relacionadas con la operación de factoring ${ }^{11}$, bajo el entendido de que la obstrucción a la libre circulación de las facturas es una práctica restrictiva de la competencia en Colombia ${ }^{12}$, y en esos casos, la Autoridad hizo referencia a la significatividad en la apertura, por la importancia que ese tema en específico podría tener frente a la obstrucción del acceso de pequeñas empresas al mercado, el bloqueo o ahogo financiero que los grandes compradores le generaban a las pequeñas empresas limitando la circulación de las facturas. La Superintendencia se refirió al tema de la significatividad explicando que la investigación podría tener frente a los tres propósitos de la Ley 1340 de 2009.

La significatividad o la aproximación a la significatividad pudo ser acertada, en tanto que no se trataba del "peso específico" de esas facturas o de los agentes del mercado, sino que podía coadyuvar a ejercer la función sancionatoria protegiendo esos propósitos a través de una investigación administrativa ${ }^{13}$.

De manera que la significatividad no agota el debate de antijuridicidad, y la jurisdicción está reconociendo la antijuridicidad como la ilicitud de la conducta o la sustancialidad de la ilicitud de la conducta. La significatividad vuelve a ser un parámetro para

11 Superintendencia de Industria y Comercio. Resoluciones 71537, 71539, 71540 y 71542 del 8 de noviembre de 2017.

12 Artículo 778 del Código de Comercio (modificado por el artículo 7 de la Ley 1231 de 2008). "Con el solo hecho de que la factura contenga el endoso, el obligado deberá efectuar el pago al tenedor legítimo a su presentación.

"Únicamente para efectos del pago, se entiende que el tercero a quien se la ha endosado la factura, asume la posición del emisor de la misma.

"En ningún caso y por ninguna razón, podrá el deudor negarse al pago de la factura que le presente el legítimo tenedor de la misma, salvo lo dispuesto en el artículo 784 del presente código.

"Toda estipulación que limite, restrinja o prohíba la libre circulación de una factura o su aceptación, se tendrá por no escrita.

"Parágrafo 1 (adicionado por el artículo 87 de la Ley 1676 de 2013). Toda retención de la factura o acto del comprador del bien o beneficiario del servicio que impida la libre circulación de la misma, constituye una práctica restrictiva de la competencia que será investigada y sancionada, de oficio o a solicitud de la parte afectada, por la Superintendencia de Industria y Comercio de conformidad con lo establecido en el artículo 16 de la Ley 590 de 2000.

"Parágrafo 2 (adicionado por el artículo 87 de la Ley 1676 de 2013). Los administradores de las sociedades comerciales están obligados en la memoria de gestión anual, a dejar constancia de que no entorpecieron la libre circulación de las facturas emitidas por los vendedores o proveedores. El Revisor Fiscal en su dictamen anual deberá pronunciarse sobre el cumplimiento de lo anterior, por parte de la administración".

13 "La significatividad también puede estar determinada por la necesidad de la autoridad de competencia de ejercer uno de los fines del poder sancionatorio, esto es, la prevenciòn general para vigilar el correcto funcionamiento de los mercados". 
la definición del plan el trabajo de la Superintendencia de Industria y Comercio; de ahí se concluye que los conceptos de antijuridicidad y significatividad no se confunden, pero sí dejan abierta la inquietud que plantea el doctor Mauricio: si se argumenta la significatividad y la significatividad es discrecional, hasta qué punto podría o no haber control sobre esa calificación.

\section{¿EN DÓNDE ESTÁ LA ANTIJURIDICIDAD?}

El parágrafo del artículo 3 de la Ley 1340 de 2009 señala que "la Superintendencia de Industria y Comercio tendrá en cuenta los propósitos de los que trata este artículo al momento de resolver la significatividad de la práctica a iniciar o no una investigación, sin que por este solo hecho se afecte el juicio de ilicitud de la conducta".

El doctor José Miguel interpreta que dicha disposición no quiere decir que sea lícito o ilícito, pero considero que la ley no puede decir lo contrario (parágrafo del artículo 3 de la Ley 1340). Es que el juicio que afirme al principio que es significativo no afecta el juicio de ilicitud, porque la ilicitud se decide al final, y si se sostiene que es ilícito desde el principio por esa apertura y por decir que es significativo, implicaría prejuzgar un comportamiento y tendrían que apartar al funcionario, porque está concluyendo que es ilícito desde el principio.

Por eso, la aclaración es que el hecho que se afirme que es significativo al principio, es decir, antijurídico, no afecta el juicio de ilicitud, porque al final hay que debatir si efectivamente es antijurídico.

Ahora bien, si la significatividad es solamente el acceso al sistema, al final se debería debatir si ese acceso se dio de manera correcta. Eso quiere decir que, si últimamente la jurisdicción ha referido que se requiere tipicidad, antijuridicidad y culpabilidad, la pregunta es cdónde está la antijuridicidad en el Decreto 2153 de 1992 y en las leyes de regulación? Porque, entonces, no se cuenta con el concepto de antijuridicidad, y la antijuridicidad supuestamente es libertad de entrada y libertad de escogencia, que es bienestar del consumidor, bienestar del productor, excedente del consumidor, excedente del productor y bienestar social (artículo 3 de la Ley 1340 de 2009 y numeral 3 del artículo 1 del Decreto 4886 de 2011).

\section{José Miguel de la Calle Restrepo}

No considero, a diferencia del doctor Gustavo, que la significatividad sea un criterio que le permite a la Superintendencia de Industria y Comercio darle un campo de acción para fijar sus prioridades y de alguna manera establecer un ámbito discrecional de decisión sobre lo significativo. Me aparto de esta postura, que ha sido la mayoritaria, bajo la cual la Autoridad de Competencia ha entendido que la significatividad es una potestad que le asigna la ley para definir, con unos criterios, esa selección.

Ahora, no considero que haya discrecionalidad, por varias razones. Una de ellas es que cuando se analiza la significatividad se olvida el derecho del denunciante, que, 
en desarrollo del derecho a la libre competencia, tiene derecho a que se investigue su denuncia. Con ello, no se quiere decir que la Superintendencia de Industria y Comercio debe investigar todo lo que se pone a su conocimiento, sino que deberían existir criterios más objetivos, claros, definidos y construidos que ofrezcan verdadera seguridad jurídica al denunciante para saber si su denuncia será o no conocida.

Aún no hay claridad sobre cuáles son los factores cualitativos y cuantitativos para la admisión. Por factores cuantitativos, se han abierto casos que involucran empresas con el $20 \%$ de participación en el mercado, se ha dejado de abrir casos con el 15\%, pero también se han abierto casos con el 6\%. De forma que, en esas circunstancias, es muy difícil para un denunciante poder predecir, bajo bases objetivas, si un caso va a ser abierto o no por la Superintendencia de Industria y Comercio, más si la teoría es que se trata de un factor discrecional y la participación de mercado no es el único elemento para definirla. De hecho, en algunas decisiones de la Autoridad de Competencia, se ha previsto expresamente que la participación en el mercado no es un factor relevante para determinar la significatividad ${ }^{14}$. Entonces, ¿cuál es su alcance en la aplicación? Es decir, llevamos años diciendo que la participación es un factor relevante y la Autoridad termina concluyendo que realmente no lo es.

Conceptualmente, es correcto concluir que debe existir un abanico de componentes cualitativos y cuantitativos, pero hace falta claridad. Dicha claridad podría lograrse mediante una guía que produzca la Superintendencia de Industria y Comercio en la que se indiquen cuáles son los umbrales, los rangos de participación, de valor de activos, o de otros indicadores en lo cuantitativo y cuáles son los criterios cualitativos, pues lo que no puede pasar es que, dado el caso de que le llega a la Superintendencia, entonces, en ese momento tome la decisión de la relevancia del mismo y, para ello, le basta con decir se necesita crear doctrina. Por eso, no se debería usar la palabra discrecionalidad en este aspecto.

\section{SIGNIFICATIVIDAD Y DISCRECIONALIDAD}

Retomando la respuesta anterior, se cuenta con discrecionalidad. En Derecho administrativo, esto significa que existen actos que son reglados y otros, actos discrecionales. Así, cla determinación de si un comportamiento es significativo o no y si se abre o no la investigación, es un acto administrativo de carácter discrecional o reglado?

\section{Gustavo Valbuena Quiñones}

Es discrecional, lo que no significa que sea caprichoso. No hay actos meramente discrecionales en un Estado que sea de Derecho. Es difícil pensar en aproximar el concepto de significatividad con base en elementos como el mercado relevante. Por ejemplo,

14 Por ejemplo, en las resoluciones 30300 del 23 de mayo de 2016 (casting) y 41412 de junio de 2018 (Bureau Veritas). 
al lado del Estadio El Campín hay puestos de comida que son de 4 o 5 personas, que ofrecen solo un par de productos después de los partidos de fútbol. ¿Cuál es el mercado relevante de proveeduría de comida después de los partidos de fútbol? Las personas salen del estadio y no buscan la comida en otra parte, solo ahí. Así, el mercado relevante podría llegar a estar acotado por estos 4 o 5 vendedores, de tal forma que si se ponen de acuerdo podrían estar afectando al 100\% del mercado relevante.

Ahora, cla participación en el mercado relevante configura la significatividad? No. La vinculación tiene que hacerse a los tres propósitos previstos en el artículo 3 de la Ley 1340 de 2009, lo que no quiere decir que ese no puede ser un caso calificado de significativo por la Superintendencia. Entonces, no es discrecional, pero sí es un tema que se tiene que construir.

Entonces, si se afirma que no hay actos meramente discrecionales, ccuál podría ser la desidia de la Superintendencia si no califica? La Superintendencia de Industria y Comercio tiene un deber de motivar la decisión y esta motivación debe llegar a lo que indica el doctor José Miguel, y es que existan elementos con los cuales se pueda construir la doctrina que permita anticipar qué criterios se van a tener en cuenta para la significatividad.

Hay que precisar que el denunciante no queda "desamparado", porque la libre competencia puede ser protegida por los jueces mediante las acciones populares, por ejemplo, o si llegan a demandar por competencia desleal, la significatividad quedaría por fuera del análisis de la demanda.

José Miguel de la Calle Restrepo

La norma colombiana refiere que se trata de un acto de trámite, pero no debería ser así en tanto que se trata de una decisión que permite o restringe el acceso al sistema.

En mi opinión, debería ser una decisión no discrecional, reglada y susceptible de recursos. Se requiere una revisión de la ley, porque finalmente, y se reitera, la libre competencia tiene tres propósitos y uno de ellos tiene clara incidencia con el consumidor, que puede ser el denunciante, titular del derecho a la competencia previsto en el artículo 333 de la Constitución Política, sin que se pierda de vista que el Derecho de la competencia es un derecho de todos.

El Derecho de la competencia no solo está pensado para los mercados como una estructura genérica, sino para las personas que pueden verse afectadas. Ahora, no solo los denunciantes tienen derecho, sino también los investigados que tienen derecho al debido proceso. En últimas, es necesario que el acceso al sistema esté reglado, con doctrina clara, específica y que las decisiones al respecto sean susceptibles de recursos.

\section{EL DERECHO DE CONTRADICCIÓN RESPECTO DE LA SIGNIFICATIVIDAD}

¿Cuál es el momento procesal en el que el investigado puede ejercer derecho de contradicción frente a la decisión tomada por la Superintendencia de Industria y Comercio 
sobre el alcance del artículo 3 de la Ley 1340 del 2009 o es una decisión en la que no cabe la contradicción del investigado?

En materia de Derecho administrativo existen los actos de trámite y los actos de fondo. El primero no tiene recurso, mientras que el segundo, sí. Sin embargo, si la Superintendencia de Industria y Comercio decide que un caso es significativo al inicio de la investigación y respecto a esta decisión se ha dicho que es un acto de trámite, nunca se tendría derecho de contradicción sobre un acto, que finalmente resuelve si se abre o no investigación. Por eso, es importante que al final se pueda debatir si el asunto es significativo o no, pues de lo contrario se presenta una situación en la que una entidad administrativa decide sin reparo alguno.

\section{Gustavo Valbuena Quiñones}

Evidentemente, cabe una controversia frente al acto sancionatorio, si la Superintendencia de Industria y Comercio que tiene la carga de la prueba no acreditó la antijuridicidad material en la infracción. Es decir, si la sustancialidad de la ilicitud no quedó acreditada, perfectamente cabe el recurso y control jurisdiccional frente a la decisión administrativa.

El debate es interesante y es si al momento de pretender la nulidad de la decisión abarca todo el procedimiento, si un cargo pudiera fundarse en que no hubo una debida demostración de la significatividad al momento de abrir la investigación, es un debate interesante. Sin embargo, para efectos de la afectación material al bien jurídico ese punto de la antijuridicidad puede fundar un recurso y una acción de nulidad.

\section{José Miguel de la Calle Restrepo}

En el caso de las empresas de casting ${ }^{15}$, la Superintendencia de Industria y Comercio planteó que solo era viable estudiar el tema de la significatividad en el momento en que se decide sobre la apertura o no de una investigación. Esto conceptualmente tiene lógica, el problema es que dicha decisión no tiene recurso.

Entonces, si aun en la voz de la Superintendencia la discusión sobre significatividad se debe dar en la apertura la dificultad se presenta en tanto esa decisión no tiene recurso, aunque sí tiene traslado. Alguien podría concluir que se le da traslado para que se pronuncie sobre lo que se plantea en la apertura y que esos comentarios que hace el investigado con apertura formal que los hizo a tiempo, y la Superintendencia de Industria y Comercio los puede estudiar en el informe motivado. Sin embargo, la realidad es que en la práctica eso es improbable, en la medida en que sería poco lógico que la Superintendencia de Industria y Comercio adelante toda una investigación para que luego de todo el tiempo que ha invertido en la investigación le dé la razón a aquel que de comienzo afirmó que la investigación no era significativa. 
De forma que existe un defecto de procedimiento, que debería ajustarse. Lo primero es que la apertura debería tener recurso y permitir explícitamente que se discuta sobre la significatividad, e inclusive, podría plantearse un "incidente de significatividad", porque, como dice el doctor Mauricio, tiene una relación con la competencia.

Es posible sostener razonablemente que si una investigación se conduce sin cumplir los estándares de significatividad, asumiendo, por ejemplo, que existiera una guía muy clara que dijera cuáles son, la Superintendencia de Industria y Comercio no tendría competencia para haber conducido esa investigación y, por lo tanto, bien podría plantearse un elemento adicional, no solo un recurso, sino que se interponga algo similar a un incidente, pues lo que no puede pasar es, como ocurre en el procedimiento actual, que no se puede discutir en el informe motivado porque es muy tarde, pero tampoco al inicio de la investigación, porque no hay recurso.

\section{Gustavo Valbuena Quiñones}

Una solución puede ser el recurso contra la decisión de cierre que podría llegar a tener el denunciante, lo que puede ser un escenario saludable para revisar los casos que tienen argumentos para soportar la significatividad.

Frente a los umbrales, en algún momento se discutió si en paralelo con lo que en materia de integraciones se consagró sobre el 20\% de participación conjunta para la notificación ${ }^{16}$, Colombia estaría preparada para establecer reglas de minimis con porcentajes, así como con medidas cualitativas y cuantitativas, para dar un elemento de significatividad diferente al general que está previsto en el artículo 3 de la Ley 1340 de 2009.

Hoy, es un debate que está abierto, es necesario hacer una verificación del Derecho comparado y, con el estado de madurez actual de la Autoridad de Competencia y del mercado, analizar si podría considerarse el establecimiento de reglas de minimis, que no excluyan la antijuridicidad de comportamientos por debajo de estos umbrales, pero que permitan ofrecer objetividad a la definición de la apertura o no de una actuación administrativa, elementos cuantitativos y cualitativos, en la medida en que también habrá comportamientos que, independiente de su umbral, se consideren inadmisibles y respecto de los cuales se justifique abrir una actuación administrativa.

\section{CONCLUSIONES}

- El artículo 3 de la Ley 1340 de 2009 en su parágrafo describe el bien jurídico tutelado en materia de derecho antimonopolio en Colombia, ya que al referirse a los propósitos, estos incluyen, de manera implícita, el bienestar social, pues este hace referencia al bienestar del consumidor y el bienestar del productor, que, a su vez, se materializan en el excedente del consumidor y el excedente del productor, de 
manera que ese bienestar social es el bien jurídico tutelado por la disposición en comento.

- Frente al artículo mencionado, debe tenerse en cuenta que la Corte Constitucional, mediante Auto 070 del 17 de abril de 2013, expresó que el mismo se encontraba derogado. No obstante, mediante en el numeral 3 del artículo 1 del Decreto 4886 de 2011 se volvió a incluir esa disposición, en la medida en que consagra como función de la Superintendencia de Industria y Comercio: "conocer en forma privativa de las reclamaciones o quejas por hechos que afecten la competencia en todos los mercados nacionales y dar trámite a aquellas que sean significativas para alcanzar, en particular, los siguientes propósitos: la libre participación de las empresas en el mercado, el bienestar de los consumidores y la eficiencia económica"17. De manera que se consagran nuevamente la significatividad y los propósitos que a esta se vinculan.

- En principio, no existió consenso sobre si la significatividad se refería a la antijuridicidad en el juicio de responsabilidad administrativa o si se trataba de un criterio que permite la organización de la Superintendencia, en cuanto a las investigaciones que se debe abrir o no. No obstante lo anterior, la totalidad de los panelistas estuvieron de acuerdo en que la antijuridicidad es un elemento necesario en todos los juicios de responsabilidad que realice la Superintendencia de Industria y Comercio. Mauricio Velandia considera que la antijuridicidad está en el artículo 3 de la Ley 1340 de 2009, hoy replicado en el numeral 3 del artículo 1 del Decreto 4886 de 2011, porque ahí se encuentra establecido el bienestar social, esto es, excedente del productor y excedente del consumidor. Los demás panelistas dentro de la conversación no señalaron en qué disposición se podía encontrar la antijuridicidad en materia de prácticas comerciales restrictivas.

- Todos los miembros del panel coincidieron en que la Superintendencia de Industria y Comercio debe probar el elemento significativo, al ser un elemento fundamental en el juicio de responsabilidad administrativa, y que este debe estar sujeto al derecho de contradicción, lo cual significa que la decisión sobre la significatividad de la conducta debe ser debatida al final de la decisión, ya que no se puede hacer desde un inicio, en la medida en que ese juicio se observa en el acto de apertura, que es un acto de trámite. 